\title{
Sin palabras: génesis y desarrollos de los estudios sobre la comunicación no verbal
}

\section{Without words: genesis and developments of the studies on non-verbal communication}

\author{
Julio César Pereiro juliopereiro3@gmail.com \\ http://orcid.org/0000-0003-2731-2971
}

Facultad de Ciencias Sociales; Universidad Nacional del Centro de la Provincia de Buenos Aires (Argentina)

\section{Resumen}

Desde sus inicios hace casi setenta años los estudios de comunicación no verbal (CNV) se han desarrollado principalmente a partir de los aportes de los campos de la psicología y la 
antropología. En este sentido, la CNV se ha abocado a la descripción de aquellos acontecimientos de la comunicación humana que trascienden las palabras dichas o escritas. El presente artículo se propone realizar un recorrido por los principales aportes en materia de CNV, desde el desarrollo inicial de la kinésica, la proxémica y la paralingüística hasta las investigaciones en micromovimientos. Asimismo, se plantea la necesidad de estudiar la CNV desde la perspectiva de la comunicación social, disciplina que ha estado en gran medida ausente en los estudios de la materia.

Palabras clave: Comunicación no verbal; Comunicación social; Kinésica; Proxémica; Paralenguaje.

\section{Abstract}

Since its beginnings almost seventy years ago, nonverbal communication studies (NVC) have been developed mainly from the contributions of the fields of psychology and anthropology. In this sense, the NVC has devoted itself to the description of those events of human communication that transcend words spoken or written. The present article proposes to carry out a tour of the main contributions in the field of NVC, from the initial development of the kinesthetic, the proxemics and the paralinguistics to the investigations in micromovements. Likewise, there is a need to study the NVC from the perspective of social communication, a discipline that has been largely absent in studies of the subject.

Keywords: Non-verbal communication; Social comunication; Kinesthetic; Proxemics; Paralanguage.

\section{Resumo}

Desde seus primórdios, há quase setenta anos, os estudos de comunicação não-verbal (CNV) foram desenvolvidos principalmente a partir das contribuições dos campos da psicologia e da antropologia. Nesse sentido, a CNV se dedicou à descrição dos eventos da comunicação humana que transcendem as palavras faladas ou escritas. O presente artigo propõe-se a percorrer as principais contribuições no campo da CNV, desde o desenvolvimento inicial da cinética, da proxêmica e da paralinguística até as investigações em micromovimentos. Da mesma forma, existe a necessidade de estudar a CNV a partir da perspectiva da comunicação social, uma disciplina que tem sido amplamente ausente nos estudos sobre $\mathrm{o}$ assunto. 
Todo comunica. Todo. No se puede no comunicar. Si algo existe, ese algo comunica. Esta premisa tan sencilla de enunciar denota la enorme complejidad de los procesos de comunicación. Ahora bien, con el objeto de avanzar en el desarrollo de la temática propuesta para el presente artículo, debemos considerar en primer lugar que todo acto de comunicación involucra un proceso de codificación y decodificación de signos. En tal sentido, y a grandes rasgos, podemos dividir la comunicación interpersonal en dos áreas: la verbal y la no verbal. La comunicación verbal hace referencia al conjunto de mensajes conformados por signos lingüísticos, mientras que el epíteto no verbal se emplea para "describir todos los acontecimientos de la comunicación humana que trascienden las palabras dichas o escritas" (Knapp, 1997, p. 41). Retomando el esquema clásico de la comunicación propuesto por Jakobson, la diferencia entre comunicación verbal y no verbal no estribaría en el canal, sino en el código. Ahora bien, es preciso aclarar que los procesos de comunicación verbal y no verbal se producen de forma conjunta y -salvo con fines analíticos- no pueden ser separados; "la comunicación no verbal no se puede estudiar aislada del proceso total de comunicación. La comunicación verbal y la no verbal deberían tratarse como una unidad indivisible" (Knapp, 1997, p. 26). Planteada en otros términos, la comunicación no verbal constituye una parte inseparable del proceso de interacción entre humanos.

Un primer acercamiento a una conceptualización de la comunicación no verbal nos la brinda Fernando Poyatos (1994a), quien la define como "las emisiones de signos activos o pasivos constituyan o no comportamiento, a través de los sistemas no léxicos somáticos, objetuales y ambientales contenidos en una cultura, individualmente o en mutua coestructuración" (p.17). Es decir que la comunicación no verbal involucra todos los procesos, conscientes e inconscientes, de codificación y decodificación (1) de todos aquellos signos que no sean lingüísticos. Asimismo, el mencionado autor manifiesta, además, que esta definición se basa en la idea de que tanto los seres humanos como el contexto que nos rodea, ya sea natural o modificado, emiten de forma permanente signos no verbales. Es decir que la CNV puede -y debe- ser abordada desde diferentes campos de estudio disciplinares, como la comunicación, la psicología, la antropología, la educación, pero también la arquitectura, la publicidad, la literatura, la pintura, la fotografía, el teatro y el cine, etc., lo cual refleja una de las principales particularidades de la CNV: la interdisciplinariedad que caracteriza su estudio. No obstante, en el presente artículo, el término comunicación no verbal se circunscribe únicamente a la forma de comunicación humana producida mediante la utilización de signos no lingüísticos.

Respecto a la importancia de la CNV, según un estudio realizado por Ray Birdwhistell, en "una conversación normal de dos personas, los componentes verbales suman menos del 35 por ciento del significado social de la situación mientras que más del 65 por ciento del significado 
social queda del lado de lo no verbal" (Knapp, 1997, p. 33), de manera tal que dos tercios de los mensajes emitidos/compartidos serán de índole no verbal.

En este punto es preciso remarcar dos errores frecuentes en la bibliografía no especializada, así como en el imaginario popular sobre la temática. El primero de ellos es emplear el término lenguaje corporal como sinónimo de comunicación no verbal. Si bien es cierto que ambos conceptos se relacionan (el lenguaje corporal es analizado por la kinésica, una de las tres áreas principales de estudio de la CNV) el mismo es solo una parte del todo más amplio que comprende la comunicación no verbal.

El otro gran equívoco es intentar analizar un signo no verbal de forma descontextualizada, es decir sin considerar la situación en la que se emplea o para qué se lo emplea, o bien el contexto en el que se inscribe. En este sentido, todo proceso de comunicación no puede ser analizado fuera de la situación donde se produce. Esto último viene a derribar un mito frecuente en el campo de la CNV en el cual se puede interpretar, por ejemplo, un determinado gesto a partir de una fotografía. Este mito tiene su origen en el año 1970, cuando el periodista Julius Fast publicó su libro El lenguaje del cuerpo, el cual rápidamente se convirtió en un bestseller. Fue su obra la que despertó el interés de gran parte de la población en la temática, aunque al mismo tiempo difundió una serie de mitos respecto a la comunicación no verbal, en especial sus alcances, y simplificó la interpretación de los signos no verbales estableciendo una tabla de equivalencia entre determinados signos y su correspondiente -e inequívoco según el autor- significado. Perduran hasta hoy día interpretaciones según las cuales, por ejemplo, si alguien se toca la nariz está mintiendo o si una mujer acaricia su cabello es señal de seducción. En este sentido, al igual que en el lenguaje oral, el significado de los signos sólo puede ser decodificado en relación con su contexto.

A modo de ejemplo, el significante fuerte tiene más de una docena de significados diferentes en castellano, y solamente podrá ser comprendido a partir del enunciado donde se enmarque. No es lo mismo afirmar: - Mi primo va al gimnasio y levanta 120 kilos en pecho, jes muy fuerte! que: - ¿Podés bajar la música por favor? Está muy fuerte.

En el primero de los casos, fuerte se relaciona con la fortaleza física, mientras que en el segundo se vincula con la intensidad del volumen. De igual modo, rascarse la nariz puede ser la delación de una mentira, pero también podría tratarse de que la persona en cuestión estuviese resfriada y le moleste respirar o bien ser sencillamente un tic nervioso (3).

Por otra parte, Poyatos (1994a) hace referencia en su obra a una estructura de los elementos presentes e inseparables en la CNV lo cual denomina la triple estructura básica de la comunicación. Ella está conformada por el lenguaje, el paralenguaje (cualidades de la voz y sus posibles modificaciones) y la kinésica (los movimientos corporales y los gestos). A estos 
últimos dos elementos se le añade la proxémica, es decir el estudio de la disposición, estructuración y uso del espacio que realizan los hablantes durante el proceso de comunicación.

En tal sentido, la kinésica, el paralenguaje y la proxémica son los tres sistemas que conforman la comunicación no verbal; los dos primeros son considerados sistemas básicos o primarios por su participación directa en cualquier acto de comunicación humana, puesto que se ponen en funcionamiento a la vez que el sistema verbal para producir cualquier enunciado; el tercero -el proxémico- es considerado como un sistema secundario o cultural, el cual actúa modificando o reforzando el significado de los elementos de los sistemas básicos. En los apartados posteriores se analizarán cada uno de estos sistemas.

\section{Breve repaso de los principales aportes a la CNV}

Si bien a lo largo de la historia diferentes autores han abordado de una u otra manera aspectos de la comunicación no verbal, es innegable como ésta ha recibido menor atención y estudio científico que la verbal, dado que consiste en un modo de transmisión de mensajes menos estructurado y de una interpretación mucho más compleja. El primer registro de una investigación científica sobre el tema data de 1872 con la publicación del libro "La expresión de las emociones en los animales y en el hombre" de Charles Darwin. Según el famoso naturalista británico, las expresiones faciales vinculadas a determinadas emociones son universales para los mamíferos, tanto humanos como animales y tienen un origen evolutivo. Dicha teoría fue fuertemente criticada durante décadas, para luego ser confirmada, un siglo después, por el psicólogo Paul Ekman.

En la primera mitad del siglo XX, gran parte del campo académico de la psicología (disciplina que tenía hasta el momento la preeminencia en investigaciones de CNV) realizó sus estudios bajo la perspectiva del conductismo, de forma tal que los desarrollos sobre los comportamientos no verbales como manifestación de emociones y pensamientos carecían de legitimidad académica y eran desestimados por los investigadores. Una notable excepción es la investigación del antropólogo argentino radicado en EE. UU. David Efron, quien en 1941 con su obra "Gesto, raza y cultura" estableció la importancia del rol de la cultura en la formación de muchos de nuestros gestos, invalidando a partir de una investigación científica las teorías nazis sobre el origen racial de los movimientos expresivos del cuerpo. De esta forma, Efron es considerado como el precursor de los estudios de las expresiones y gestos en la interacción social. 
La década del 1950 marcó el origen de la investigación sistemática en temas relacionados con la comunicación no verbal. De hecho, el término fue utilizado por primera vez en 1956 en el libro del psiquiatra Jürgen Ruesch y el fotógrafo Weldon Kees Comunicación no verbal: notas sobre la percepción visual en las relaciones humanas en el cual el autor proporciona un primer acercamiento sobre los usos de los diferentes sistemas que conforman la comunicación, así como su proceso de codificación.

Asimismo, destacan los avances realizados por Ray Birdwhistell, Edward T. Hall y George Trager. Todos ellos trabajaron durante los '50 para el Instituto de Servicios Extranjeros (4), y fueron quienes organizaron el campo de estudio de la comunicación no verbal, definiendo y delimitándolo. En esa instancia el desarrollo de los estudios en CNV estaba impulsado en gran medida por una serie de investigaciones patrocinadas por el gobierno estadounidense.

En 1952 Birdwhistell publica Introducción a la Kinésica acuñando de este modo el término para referirse a lo que coloquialmente se denomina lenguaje corporal, es decir los gestos, las posturas y todos aquellos movimientos del cuerpo utilizados de forma conciente o no para comunicarnos. Asimismo, Birdwhistell fue un acérrimo defensor del carácter cultural y aprendido de los gestos y las expresiones. En 1958 Trager divulga un breve artículo de solo doce páginas titulado Paralingüística una primera aproximación en el cual presenta una nueva disciplina para un objeto de estudio apenas definido: el paralenguaje, el cual refiere a todos aquellos componentes sonoros que acompañan a los signos verbales. Al igual que su colega Birdwhistell, propone el carácter cultural del paralenguaje. Finalmente, en 1959 el antropólogo Edward T. Hall da a conocer su trabajo El lenguaje silencioso tras varios años de investigación del uso del espacio por los seres humanos, e introduce por primera vez el concepto de proxémica, la cual estudia la conducta humana en relación con el espacio en el que se desenvuelve.

Son numerosos los estudios e investigadores en la década de 1960, dentro de los cuales destaca el psicólogo Paul Ekman, quién recuperó las teorías evolucionistas de Darwin y demostró el carácter universal de las expresiones faciales de las emociones básicas. En 1977 Albert Mehrabian genera una de las grandes controversias en el campo de la CNV con su célebre regla de las proporciones del lenguaje verbal o simplemente regla de $7-38$ - 55 por la cual, en la transmisión de un mensaje oral, solamente el 7 por ciento es verbal, mientras que el 38 por ciento corresponde al paralenguaje y el 55 por ciento restante remite a la kinésica. Tal afirmación ha sido malinterpretada, ya que la misma sólo puede aplicarse a determinados casos específicos y no constituye por ningún motivo una generalidad.

En la década de 1980 Philippe Turchet comienza sus estudios sobre comunicación no verbal, para en el año 1996 terminar de sistematizar y fundar la Sinergología, es decir la disciplina 
encargada de leer e interpretar la comunicación no verbal. Asimismo, este autor defiende el carácter aprendido de los gestos, retomando las posturas de Birdwhistell y Hall.

En síntesis, la comunicación no verbal aún permanece en su fase de organización y desarrollo, puesto que se sigue trabajando en la identificación de los sistemas no verbales, así como su clasificación y descripción. Es una disciplina relativamente nueva y con un amplio potencial para investigar.

\title{
La kinésica
}

La Kinésica (5) fue fundada por el antropólogo Ray Birdwhistell y estudia de manera sistemática los movimientos y posiciones corporales. En tal sentido, Fernando Poyatos (1994b) define a la Kinésica como

\begin{abstract}
los movimientos corporales y posiciones resultantes o alternantes de base psicomuscular, conscientes $\mathrm{o}$ inconscientes, somotogénicos o aprendidos, de percepción visual, auditiva, táctil o cinestésica (individual o conjuntamente), que, aislados o combinados con las coestructuras verbales y paralingüísticas y con los demás sistemas somáticos y objetuales, poseen un valor comunicativo o no (p. 186).
\end{abstract}

Del mismo modo, el comportamiento kinésico, según el doctor en comunicación Mark Knapp (1997), "comprende de modo característico los gestos, los movimientos corporales, los de las extremidades, las manos, la cabeza, los pies y las piernas, las expresiones faciales, la conducta de los ojos y también la postura" (p. 17). En otras palabras, la kinésica estudia la interpretación de los movimientos corporales, los cuales "matizan el significado de los enunciados verbales, incluyéndose, además, dentro de él, aspectos tan relevantes como la mirada o el contacto corporal" (Cesteros 2006: 61). Los principales elementos que conforman el campo de estudio de la kinésica son, entonces, la postura corporal, los gestos, las miradas (oculésica) y las expresiones faciales (denominadas microexpresiones por Paul Ekman). En este sentido, la postura corporal refiere a la disposición del cuerpo, así como la orientación del mismo o de una de sus partes en relación al entorno u otros sujetos. Al respecto, Flora Davis (1998) manifiesta que la postura es el elemento más sencillo de observar y de interpretar de todo el comportamiento no verbal; además, asegura la autora "es preocupante saber que algunos movimientos corporales que teníamos por arbitrarios son tan circunscritos, predecibles y -a veces- reveladores; pero por otra parte, es muy agradable saber que todo nuestro cuerpo responde continuamente al desenvolvimiento de cualquier encuentro humano" (p. 35). En 
cuanto a los gestos, Mark Knapp (1997), a partir de la propuesta de Paul Ekman y Wallace Friesen, presenta una clasificación de los mismos agrupándolos en cinco categorías:

- Emblemas: son signos emitidos intencionalmente cuyo significado es compartido por otros. De este modo, los emblemas pueden reemplazar palabras o frases sin temor a una interpretación errónea en términos de Poyatos. Un ejemplo de emblema es extender el pulgar hacia arriba con el resto de los dedos cerrados como señal de que todo está bien. Ahora bien, al igual que con los signos lingüísticos, los emblemas son culturales y también deben ser interpretados en relación con su entorno. En algunos países, como Grecia, ese mismo gesto es considerado un insulto. Del mismo modo, ese movimiento ejecutado por una persona al costado de una ruta adquiere un significado completamente diferente.

- Ilustradores: estos gestos se realizan de forma simultánea a la comunicación verbal forman parte de este y lo enriquecen. Se utilizan para representar visualmente lo que se dice. En otras palabras, tienen como finalidad clarificar o complementar el discurso hablado, como por ejemplo mostrar dos dedos extendidos cuando se habla de un par, señalar con el dedo índice el lugar o la persona sobre lo que se habla, indicar con las manos la forma o las dimensiones de un objeto al que se refiere, etc. En síntesis, cualquier movimiento del cuerpo que cumpla un rol auxiliar en la comunicación no verbal, es un ilustrador.

- Reguladores: por medio de estos gestos es posible dirigir u organizar la interacción producida en una comunicación verbal, es decir que los mismos buscan facilitar el flujo de la comunicación, como por ejemplo para iniciar o finalizar una interacción, ceder el turno de la palabra, o tomar la iniciativa para hablar. A diferencia de las categorías anteriores, los gestos reguladores se emplean generalmente de forma inconsciente, ya sea con la cabeza, la mirada o en menor medida las manos. Los reguladores más frecuentes son los de aprobación o negación con la cabeza, ofrecer la mano para saludar o levantarla para indicarle a nuestro interlocutor que se detenga.

- Expresiones emocionales: estos gestos expresan estados anímicos o muestras de afecto. Los mismos pueden ser espontáneos o intencionales y cumplen un rol importante en la socialización, ya que permiten comunicar nuestros sentimientos. Por medio de estos gestos se expresan la ansiedad o tensión del momento, el sufrimiento, la alegría, el desagrado, etc. Se pueden apreciar en las expresiones faciales, así como en los movimientos de brazos y la postura corporal. En este sentido, esta clase de gesto cumple un rol similar a los ilustradores puesto que también acompañan a la palabra, y le otorgan un mayor dinamismo; pero difieren en que los primeros reflejan el estado emotivo de la persona, en tanto que el ilustrador es emocionalmente neutro. 
- Adaptadores: de todos los gestos, quizás estos sean los más interesantes para analizar, ya que los mismos tienen como finalidad ayudar a controlar las emociones propias de los sujetos, es decir que tienen una función de autoregulación, de manera tal que le permiten a las personas adaptarse a su entorno a partir de un control de su estado emocional. Los adaptadores son los comportamientos que con frecuencia se los denomina tics nerviosos, y los mismos se realizan principalmente de forma inconsciente. Es importante destacar que los adaptadores se intensifican con la tensión y el estrés y pueden estar dirigidos hacia uno mismo (como por ejemplo tocarse la cara o rascarse el antebrazo) o hacia un objeto (jugar con un anillo o una lapicera).

Dentro de los gestos adaptadores, Philippe Turchet (2011) propone la existencia de lo que él denomina micromovimientos, es decir gestos que expresan las pulsiones reprimidas por las personas. Existen tres tipos de micromovimientos: en primer lugar, los micropicores, los cuales son una respuesta sensitiva a la vasodilatación de los músculos que el sujeto desea accionar pero que debe controlar. Los mismos manifiestan una contradicción entre los pensamientos, sentimientos y deseos de un sujeto y los actos que éste realiza. De esta manera, la persona de forma inconsciente se rasca la zona en la que siente comezón. Ahora bien, es preciso diferenciar entre una picazón natural, por ejemplo, producida por la irritación en la piel a causa de la picadura de un insecto, de los micropicores. Estos últimos se dan principalmente en situaciones de tensión. Por otro lado, están las microcaricias, estas indican bienestar, así como una sensación placentera de conformidad, ya sea con la situación, con el sujeto mismo o su interlocutor. La caricia dirigida hacia su propio cuerpo expresa en muchas oportunidades un deseo inconsciente de dirigir la caricia al otro. Finalmente, se encuentran las microfijaciones que reflejan un alto grado de concentración, como por ejemplo sostener la mano con el mentón. Por lo general, cuando se observa una microfijación, el resto del cuerpo permanece inmóvil.

\section{La proxémica}

La proxémica es la disciplina que estudia el conjunto de comportamientos no verbales en relación a la organización del espacio, así como las distancias que guardan los sujetos en un acto comunicativo a partir del análisis de la forma en que las personas perciben y usan el espacio con los demás, lo que constituye un factor clave en la decodificación e interpretación del discurso. Planteado en otros términos, el objeto de estudio de la proxémica se compone por las prácticas vinculadas al comportamiento, al ambiente, las costumbres y creencias de una 
comunidad que se relacionan con el concepto, el uso y la distribución del espacio, así como con las distancias culturales que mantienen las personas en interacción. Al respecto, Ana María Cestero (2006) considera que

\begin{abstract}
el sistema proxémico está conformado por los hábitos relativos al comportamiento, al ambiente y a las creencias de una comunidad que tienen que ver con la concepción, el uso y la distribución del espacio y con las distancias culturales que mantienen las personas en interacción" (p. 63).
\end{abstract}

De este modo, es preciso remarcar que la utilización del espacio se encuentra directamente atravesada por las normas culturales, las cuales establecen diversas normas en el protocolo social y en la interacción pública.

El antropólogo estadounidense Edward T. Hall (1973) fue quién acuño el término proxémica y es considerado el principal referente de esta disciplina, a la cual definió como "el estudio de las relaciones del hombre con el espacio que le rodea, en el que se comunica con hechos y señales" (p. 75). Según este autor, el ser humano utiliza de forma sistemática las distancias que lo separan de otros miembros de su especie, entendiendo este espacio como la distancia física que se mantiene respecto a otros sujetos, las cuales producen mensajes tales como confianza, interés, agrado, apatía, disgusto, etc. En síntesis, el análisis proxémico puede comunicar mucho sobre la relación entre dos o más personas ubicadas en un mismo espacio.

Para Hall (1973), en el transcurso de sus interacciones cara a cara, el ser humano utiliza cuatro distancias: estas son la distancia íntima, distancia personal, distancia social y distancia pública. Resulta interesante destacar que las distancias personal y social están presentes en el reino animal también, mientras que la íntima y la pública son propias de las relaciones humanas. A continuación, se explicarán las características principales de cada una de estas distancias:

- Distancia íntima: es característica de una relación con un alta carga emocional y estima. Abarca desde el contacto físico permanente hasta los 45 centímetros de distancia entre los interlocutores. En la cultura occidental, esta distancia está reservada para quienes comparten un alto grado de confianza, afecto o bien familiaridad.

- Distancia personal: la interacción se realiza entre los 45 y 120 centímetros de distancia. Esta es la distancia más habitual que se emplea entre personas que comparten una relación de amistad, así como en el trato cotidiano. Asimismo, en esta distancia es común que se produzca algún tipo de contacto físico casual, como tocar el hombro o una palmada suave en la espalda. 
- Distancia social: es la que se emplea en la interacción en espacios públicos con personas desconocidas o con las que se tiene escasa cercanía o confianza. Abarca desde los 120 a los 270 centímetros.

- Distancia pública: se emplea principalmente para hablar en público y frente a varias personas. En esta distancia la interacción comunicacional es menos frecuente. Se la utiliza principalmente en conferencias y durante el dictado de clases y espacialmente se ubica a partir de los 270 centímetros de distancia.

Asimismo, Hall enfatiza la importancia de la cultura en la forma en la que las personas interpretan y se apropian de los espacios, de manera tal que diferentes culturas no necesariamente empleen del mismo modo las distancias anteriormente mencionadas. Por ejemplo, menciona Hall (1973), las personas que han crecido en grandes ciudades y que han vivido rodeadas de gente constantemente, por lo general aceptan a personas a menor distancia con mayor facilidad; en cambio, las personas provenientes de zonas rurales están habituadas a una mayor distancia entre los interlocutores.

\section{La paralingüística}

La última de las tres grandes áreas de estudio que conforma la CNV es la paralingüística, también conocida como paralenguaje, la cual analiza los aspectos no semánticos del lenguaje, como por ejemplos las diferentes cualidades de la voz, así como el uso de las pausas y los silencios. Parafraseando a Mark Knapp (1997), el paralenguaje "se refiere a cómo se dice algo y no a qué se dice. Tiene que ver con el espectro de señales vocales no verbales establecidas alrededor del comportamiento común del habla" (p. 24). Es decir que el paralenguaje se centra en la forma y no en el contenido, ya que el análisis se focaliza en el cómo se expresa un enunciado, más allá del enunciado en sí mismo. Por medio del paralenguaje es posible conocer el estado de ánimo así como las intenciones de una persona.

En cuanto a los principales elementos que componen el paralenguaje, Fernando Poyatos (1994b) propone una extensa clasificación en la cual se plantean cuatro grandes categorías de análisis: las cualidades primarias de la voz: son aquellos rasgos distintivos de la voz, como el tono, el volumen y el ritmo; los calificadores: estos remiten a los diferentes tipos de voces; los diferenciadores: expresan reacciones fisiológicas o emocionales como por ejemplo la risa o el llanto; y los alternantes: son los sonidos producidos por las personas que no poseen un significado semántico pero sí comunicacional, como por ejemplo chistar. Asimismo, dentro del 
paralenguaje, se abordan también las pausas y los silencios, es decir las ausencias de emisión de sonidos -ya sean éstas voluntaria o no- que se presentan en el proceso de comunicación. Cabe destacar que, de las tres grandes áreas de la CNV, la paralingüística es la que ha recibido menos atención por parte de los investigadores, en gran parte debido a la complejidad que requiere su análisis y en muchos casos a la dificultad que presenta separarlo analíticamente- de otras áreas de la CNV. En tal sentido, el estudio de la paralingüística ha quedado opacado por la kinésica -en mayor medida- y la proxémica, quedando de este modo relegado a un segundo plano.

\section{Conclusión}

En el análisis que se propuso este artículo se destaca la multiplicidad de disciplinas que abordan la comunicación no verbal, en especial la antropología y la psicología. Mientras que, al mismo tiempo, resaltan por su ausencia los aportes desde el campo de la comunicación social. En efecto, un comunicador social cuenta con las herramientas para investigar los elementos de la comunicación no verbal y en este proceso comprenderlos y analizarlos. Dichos elementos como se destacó a lo largo del artículo- son inescindibles del proceso de comunicación entre las personas.

Por ello, es que resulta necesario incluir y comenzar a estudiar la CNV desde la perspectiva de la comunicación social, ya sea -por mencionar sólo unos ejemplos- en la medida en que los diferentes elementos de CNV se hallan tamizados por los medios de comunicación masiva o bien por su importancia en la constitución de las relaciones al interior de las organizaciones sociales (comunicación institucional).

Notas

(1) Según Poyatos (1994a) existen tres posibles decodificaciones por parte del receptor: una decodificación correcta, en la cual el receptor reconoce tanto el gesto como el significado; una decodificación cero, en esta el receptor no percibe el gesto o no le ha dado importancia, y finalmente una decodificación errónea, en la que el receptor es consciente del gesto realizado por el emisor, pero le otorga otro significado.

(2) El psicólogo estadounidense Paul Ekman, uno de los principales referentes en la detección de mentiras a partir de la CNV nos habla del riesgo de Brokaw (2015), el cual se relaciona con no atender a las diferencias individuales, intentar aplicar una regla general a la totalidad de casos particulares en el análisis del comportamiento no verbal. 
(3) El Instituto de Servicios Extranjeros es la principal institución del gobierno estadounidense para formar a los empleados (diplomáticos) que deberán prestar servicios en otros países, en el cual se instruye no solo en el idioma sino también en los aspectos culturales.

(4) Diferentes autores -y traducciones al español- han adoptado los términos cinésica, kinésica y quinésica, los cuales son todas traducciones del vocablo inglés kínesics, que es a su vez una derivación del griego kinesis que significa movimiento.

\section{Bibliografía}

Cestero, A. M. (2006). La comunicación no verbal y el estudio de su incidencia en fenómenos discursivos como la ironía. Alcalá, España: Universidad de Alcalá.

Davis, F. (1992). La comunicación no verbal. Madrid, España: Alianza Editorial.

Ekman, P. (2015). Cómo detectar mentiras. Una guía para utilizar en el trabajo, la política y la pareja. Buenos Aires, Argentina: Editorial Paidós.

Hall, E. (1973). La dimensión oculta. México: Editorial Siglo XXI.

Knapp, M. (1997). La comunicación no verbal. El cuerpo y el entorno. México: Editorial Paidós.

Poyatos, F. (1994a). La comunicación no verbal I: Cultura, lenguaje y conversación. Madrid, España: Editorial Istmo.

Poyatos, F. (1994b). La comunicación no verbal II: Paralenguaje, kinésica e interacción. Madrid, España: Editorial Istmo.

Turchet, P. (2011). El lenguaje del cuerpo. Bilbao, España: Ediciones Mensajero. 